\title{
PROPERTIES OF RS5 AND OTHER SUPERALLOYS CAST USING THERMALLY CONTROLLED SOLIDIFICATION
}

\author{
M. L. Gambone', S. B. Shendye ${ }^{2}$, P. Andrews ${ }^{3}$, W. Chen ${ }^{4}$, \\ M. N. Gungor ${ }^{5}$, J. J. Valencia ${ }^{5}$, and M. L. Tims ${ }^{5}$ \\ ${ }^{1}$ Rolls-Royce, Indianapolis, IN; ${ }^{2}$ PCC Structurals, Inc., Portland, OR; ${ }^{3}$ Rolls-Royce plc, Derby, UK; \\ ${ }^{4}$ West Virginia University, Dept of Mechanical and Aerospace Engineering, Morgantown, WV; \\ ${ }^{5}$ Concurrent Technologies Corporation, Johnstown, PA
}

\begin{abstract}
$\underline{\text { Abstract }}$
This paper describes the evaluation of three superalloys-IN718, IN939, and RS5-cast using a new technology called thermally controlled solidification (TCS). The TCS casting technology enables the casting of large, complex, thin-walled components which have heretofore been impossible to cast with conventional investment casting methods. The characteristics of the candidate alloys in the TCS cast condition were analyzed for castability, weld reparability, microstructure, thermal stability, and mechanical properties. The RS5 alloy, recently patented, was also examined to optimize post casting heat treatment. The goal of this evaluation was to select the best alloy with which to conduct a component demonstration as part of a U.S. Navy manufacturing technology program. While all the alloys demonstrated adequate castability and weld reparability, the alloy identified as the best candidate was RS5. This decision was based on the superior tensile properties of TCS cast RS5.
\end{abstract}

\section{Introduction}

Many aircraft propulsion systems include large, complex, fabricated components that are expensive to manufacture, inspect, and maintain. Conventional investment casting technology is not sufficient to produce castings to supplant these fabricated structures. Critical to economically producing such a one-piece casting is a newly developed technology, proprietary to PCC Structurals, Inc., called thermally controlled solidification (TCS). The TCS process enables the casting of large (diameters as great as $1 \mathrm{~m}$ ), thin walled $(\sim 1.5 \mathrm{~mm})$ superalloy components. The goal of the U.S. Navy manufacturing technology program that funded this work was to demonstrate TCS technology by replacing a fabricated component with a one-piece casting and, in doing so, create a significant cost savings. The demonstration component selected was the diffuser case for the $\mathrm{AE} 1107 \mathrm{C}$ engine manufactured by Rolls-Royce for the V-22 Osprey tiltrotor aircraft.
The TCS process, which is critical to the success of the program, involves preheating the invested mold inside a furnace, pouring the molten alloy into the mold cavity, and withdrawing the heater. The mold is preheated in the TCS furnace in such a manner that the lower half of the total mold height is at a temperature close to, but not below, the solidus temperature of the alloy to be poured in the mold cavity. In addition, the upper half section of the mold is heated in such a way that its temperature is close to the liquidus temperature of the alloy. The molten alloy is then introduced into the mold cavity through the inlet at the top of the mold, at the end of the preheat cycle.

Once the alloy is poured into the mold cavity, the heater assembly used to preheat the mold is withdrawn, while the mold remains stationary. The ratio of the gradient, $G$, on the mold to the rate of movement of the solidification front in the mold cavity, $R$, is closcly monitorcd during the withdrawal process. G/R values of greater than $100 \mathrm{~F}$-min/square inch are realized when the heater withdrawal rates range from about $7.5 \mathrm{in} . / \mathrm{hr}$ to $30 \mathrm{in} . / \mathrm{hr}$. The achievement of adequate value of $G / R$ is critical to the quality of the castings.

During solidification, the molten alloy decreases in volume. This reduction in volume of the alloy is compensated by the still molten alloy in the gates on the mold as well as by the molten alloy near the top end of the mold. Appropriate withdrawal speed of the heater ensures that this and the interdendritic shrinkage is fed, resulting in clean, shrinkage-free equiaxed castings. With the TCS process, geometrically complex structural castings are produced at reduced cost, and the costs associated with fabrication are eliminated. Both significantly reduce the total component cost.

Also critical to the program success is the demonstration of a superalloy that is castable via the TCS process and that has the required mechanical properties. The material from which the 
diffuser is currently fabricated is Ti-6242S. Superalloys are approximately twice as dense as titanium alloys; therefore, a direct material substitution of a cast superalloy for titanium would impose an unacceptable weight penalty in this application. Thus, the goal of this work was to select and characterize a superalloy with sufficient specific strength to allow a weight neutral substitution of a one-piece casting for the titanium alloy fabrication. Of the three nickel-based superalloys evaluated in this studyIN718, IN939, and RS5-IN718 was selected because it is commonly used in the conventionally cast condition and is well characterized. In addition, IN718 is readily weld repairable. The alloy IN939 is known to have improved strength at elevated temperatures, but it is not as amenable to weld repair as IN718. RS5 is a newly developed alloy, patented by Rolls-Royce plc, that has also demonstrated superior elevated temperature properties to IN718 in the conventionally cast condition and was designed to be weld repairable. None of these alloys had been thoroughly characterized in the TCS cast condition.

The aim of the research discussed in this paper was to determine the optimum alloy with which to continue the component development: the alloy most likely to enable achievement of the goal of weight-neutrality for the engine application. In this paper, the relative TCS castability of three candidate superalloys-IN718, IN939, and RS5-is evaluated. The mechanical properties and microstructure of the TCS cast alloys are analyzed as well. The response of the RS5 alloy to cooling rate and various heat treatment schedules has also been addressed.

\section{Castability Evaluation}

\section{Experimental Procedure}

Four different casting shapes, shown in Figure 1, were cast in all three alloys-IN718, IN939, and RS5-to examine their relative castability. The typical chemical composition of the alloys used is given in Table I. Molds produced from the wax patterns of the shapes were invested and cast using the TCS process. Each of the castings was non-destructively tested using x-ray and fluorescent penetrant inspection (FPI) techniques for surface and internal shrinkage porosity and shell-related and other casting defects such as hot tearing and cold shuts. These are standard techniques used to evaluate the soundness of investment castings.

After $\mathrm{x}$-ray and FPI inspection and volumetric non-fill evaluation, the non-concentric ring castings of each alloy in the as-cast condition were cut-up at four different locations for microstructure evaluation. All the weld cavities on the weld test ring castings were ground, cleaned using standard techniques, and welded using the respective alloy filler wire. Welded test rings were heat treated, and the welded blanks were excised from the ring for microstructural evaluation and mechanical testing. The wagon wheel castings in all three alloys were welded in 10 different locations, heat treated, and sectioned for microstructure evaluation. There was no microstructure evaluation performed on the hot tear casting configuration.

\section{Results of Castability Study}

$\underline{X-r a y}$ and FPI Evaluation FPI results for the non-concentric ring showed a few minor shell-related defects in all three alloys. This is not unusual in investment castings. There were no $\mathrm{x}$-ray defects in the IN718 ring other than a minor amount $(\sim 0.5 \%)$ of non-fill. The IN939 ring revealed several hot tears and the greatest amount of non-fill $(\sim 0.2 \%)$ of all three alloys. The non-fill observed in all three alloys was in the thinnest section of the inner ring of the non-concentric ring casting. In FPI the RS5 ring demonstrated three minor hot tears and the least amount of non-fill $(\sim 0.2 \%)$ of the three alloys tested. These hot tears were not in the thin-wall section of the ring, but in the ribs connecting the inner and the outer ring. X-ray inspection of the RS5 ring did not show any additional defects. Based on these results, RS5 was the best alloy in filling thin wall molds, and IN718 was rated most hot tear resistant. Alloy IN939 performed the worst of the three alloys in both categories.

Table I Typical Chemical Composition in Weight Percent of the Alloys IN718, IN939, and RS5

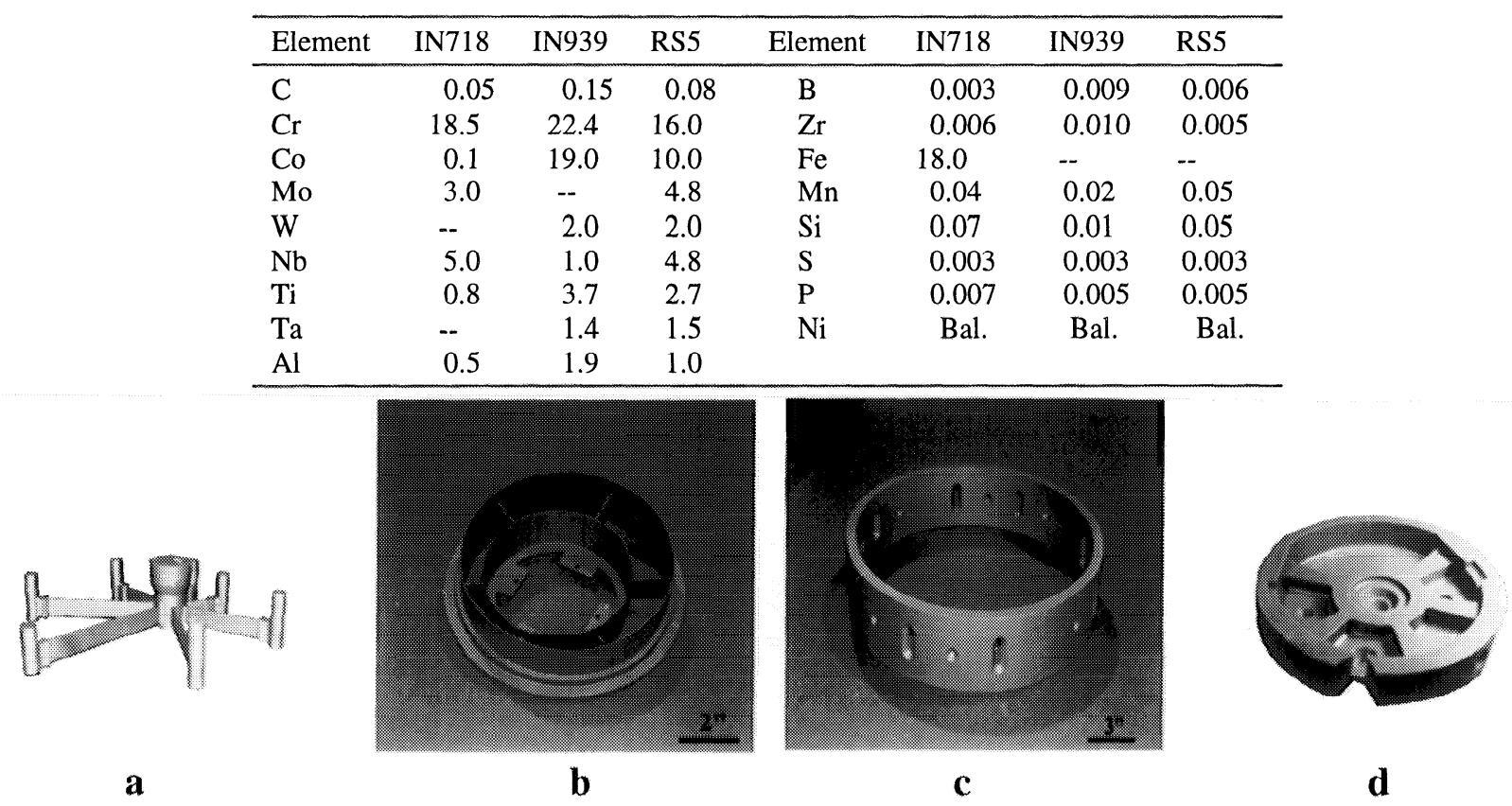

Figure 1: Castability test castings: (a) hot tear, (b) non-concentric ring, (c) weld ring, and (d) wagon wheel. 
No x-ray or FPI defects were observed in any of the weld test rings inspected in the welded and fully heat treated condition. This indicated that all three alloys are weldable. IN939 was the most difficult alloy to weld, while IN718 was the easiest to weld, as anticipated. Similar to the weld test rings, no x-ray or FPI defects were found in the cavities in the wagon wheel in the fully welded and heat treated condition in any of the three alloys.

The x-ray and FPI results for the hot tear castings were in contrast to the results found in the non-concentric ring castings. Observation of the hot tear configuration showed that RS5 performed worst of the three alloys. The RS5 casting had $10.16 \mathrm{~cm}$ of hot tear length compared to $5.33 \mathrm{~cm}$ for IN939 and $9.84 \mathrm{~cm}$ for IN718. The RS5 casting also demonstrated the maximum amount of shrinkage in FPI $(129.3 \mathrm{~cm})$ but the least in x-ray $(26.87 \mathrm{~cm})$ compared with FPI and x-ray shrinkage of $49.78 \mathrm{~cm}$ and $42 \mathrm{~cm}$, respectively, for IN718, and $60 \mathrm{~cm}$ and $31.34 \mathrm{~cm}$, respectively for IN939.

Microstructural Evaluation Figure 2 shows a photomicrograph of the RS5 alloy microstructure in the as-cast condition. The needlelike structure in the RS5 alloy is believed to be the Nb-rich $\eta$ phase. Laves phases typically observed in IN718 in the as-cast condition were eliminated by heat treatment; no segregation was found in the IN939 alloy castings after full heat treatment. Typical grain size in the non-concentric ring castings ranged between $0.75 \mathrm{~mm}$ to $1.25 \mathrm{~mm}$ in all three alloys. In Table II the grain size of both thin and thick regions in the base metal of the wagon wheel casting is shown for all three alloys.

Results of the shrinkage evaluation of the non-concentric ring casting showed that the RS5 alloy exhibited the best filling characteristics compared to the other two alloys. The maximum percent shrinkage was $1.5 \%$ for RS5, $2 \%$ for IN939, and $5.1 \%$ for IN718; the maximum size of the shrinkage was $1.78 \mathrm{~mm}$ for RS5, $3.35 \mathrm{~mm}$ for IN939, and $4.14 \mathrm{~mm}$ for IN718. No internal shrinkage defects were found in the longitudinal sections of the welded and heat treated blanks sectioned from the weld test ring castings. No defects of any kind were observed in the base metal or the heat affected zone (HAZ) of the welded blanks in any of the alloys. A grain size of about $0.38 \mathrm{~mm}$ was measured in the weld and between $3.8 \mathrm{~mm}$ and $5.0 \mathrm{~mm}$ was measured in the base metal of all the alloy castings. These results indicate all these alloys develop a similar grain size in the TCS process for section thickness of about $1.4 \mathrm{~cm}$ and that grain size in the range of $5.0 \mathrm{~mm}$ in the base metal does not pose a problem in welding.

The 10 different locations on the wagon wheel that were welded simulated thick- and thin-wall welding and welding in fillets. No shrinkage defects were observed in any of the 10 welds in any of the alloy castings. It may be noted (Table II) that, in general, the grain size of the weld metal was significantly finer than that of

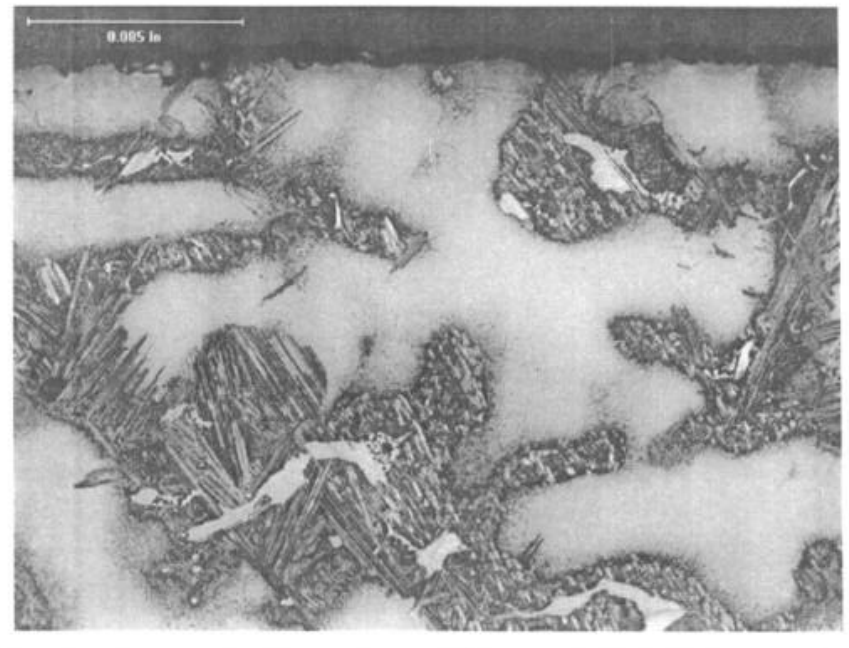

Figure 2: Microstructure of RS5 in the as-cast condition.

the base metal and that the grain size of the weld metal on thinner base metal was finer than that of welds on the thicker base metal. This effect is caused by the faster solidification rates that accompany welding. A more detailed discussion of these results can be found elsewhere $[1,2]$.

\section{$\underline{\text { RS5 Characterization }}$}

The RS5 alloy was patented by Rolls-Royce plc in 1994 for use in high temperature cast structures. Due to its relative immaturity in comparison to IN718 and IN939, more extensive characterization of RS5 alloy microstructure and property response to processing was conducted in this study. Several heat treatment variations were also evaluated to optimize the mechanical performance and stability of the alloy.

\section{Continuous Cooling Transformation Results}

Differential thermal analysis (DTA) and differential scanning calorimetry (DSC) techniques coupled with scanning electron microscopy energy dispersive spectroscopy (SEM-EDS) were utilized to study the phase transformations and develop a partial continuous cooling transformation diagram for the RS5 alloy. The liquidus of this alloy was $1330^{\circ} \mathrm{C}$ and $1312^{\circ} \mathrm{C}$ by cooling at rates of $1^{\circ} \mathrm{C} / \mathrm{min}$ and $40^{\circ} \mathrm{C} / \mathrm{min}$, respectively. During solidification, the MC-type carbide forms at $50^{\circ} \mathrm{C}$ and $60^{\circ} \mathrm{C}$ below the liquidus cooling at $1{ }^{\circ} \mathrm{C} / \mathrm{min}$ and $40^{\circ} \mathrm{C} / \mathrm{min}$, respectively. At approximately $1190^{\circ} \mathrm{C}$, a eutectic reaction starts and finishes at $1140^{\circ} \mathrm{C}$ for the slower cooling rate and $1090^{\circ} \mathrm{C}$ for the faster cooling rate. This transformation is similar to that for a $\delta$-eutectic phase, which has

Table II Grain Size Evaluation of Wagon Wheel Weld Metal and Base Metal in Alloys IN718, IN939, and RS5

\begin{tabular}{lccccc}
\hline $\begin{array}{c}\text { Alloy/sample } \\
\text { location }\end{array}$ & $\begin{array}{c}\text { Avg. grain } \\
\text { size, } \mathrm{mm}\end{array}$ & $\begin{array}{c}\text { Alloy/sample } \\
\text { location }\end{array}$ & $\begin{array}{c}\text { Avg. grain } \\
\text { size, mm }\end{array}$ & $\begin{array}{c}\text { Alloy/Sample } \\
\text { location }\end{array}$ & $\begin{array}{c}\text { Avg. grain } \\
\text { size, mm }\end{array}$ \\
\hline IN718 thin BM* & 1.0 & IN939 thin BM* & 1.5 & RS5 thin BM* & 1.0 \\
IN718 thin WM* & 0.38 & IN939 thin WM* & 0.25 & RS5 thin WM* & 0.25 \\
IN718 thick BM* & 0.76 & IN939 thick BM* & 3.0 & RS5 thick BM* & 2.5 \\
IN718 thick WM* & 0.64 & IN939 thick WM* & 0.50 & RS5 thick WM* & 0.38 \\
\hline
\end{tabular}

*BM and WM stand for base metal and weld metal, respectively. 
been reported to occur in alloy René 220C [3]. X-ray diffraction of slower cooled samples revealed the presence of Laves phases; it is believed to have been formed in the same temperature range as the $\delta$-like eutectic between $1190^{\circ} \mathrm{C}$ and $1140^{\circ} \mathrm{C}$. Accuratemeasurements of the solidus temperature on cooling were not possible; however, a solidus temperature of approximately $1179^{\circ} \mathrm{C}$ was estimated from the on-heating curves at $20^{\circ} \mathrm{C} / \mathrm{min}$. Further cooling of the as-cast microstructure indicated the precipitation of the plate-like $\eta$-phase between $1080^{\circ} \mathrm{C}$ and $980^{\circ} \mathrm{C}$ at a cooling rate of $5^{\circ} \mathrm{C} / \mathrm{min}$. The precipitation of the $\gamma^{\prime}$ was not observed in the DSC or DTA curves. Figure 3 shows the various solidification phases.

DSC analysis of hot isostatic pressed (HIPed), solution treated $\left(1160^{\circ} \mathrm{C}\right)$, and aged RS5 specimens was used to develop the partial continuous cooling transformation diagram in a cooling rate range of 1 to $20^{\circ} \mathrm{C} /$ min shown in Figure 4 . Two solid-state transformations were observed in this cooling rate range, one that begins to precipitate between $1050^{\circ} \mathrm{C}$ and $1010^{\circ} \mathrm{C}$ as the cooling rate increases and another phase transformation that occurs at approximately $980^{\circ} \mathrm{C}$. The higher temperature precipitate is $\eta$ phase; its transformation temperature range appears to coincide with the range of solubility for the $\delta$-phase in the René $220 \mathrm{C}$ alloy [3]. The lower temperature phase also appears to be $\eta$ phase, but its nucleation may have occurred in the matrix rather than at grain boundaries or "ghosts" of the interdendritic segregation regions. Work is still in progress to elucidate this phenomenon. The $\gamma^{\prime}$ and $\gamma^{\prime \prime}$ phase precipitation fields were observed using DSC to extend from just below $930^{\circ} \mathrm{C}$ to about $580^{\circ} \mathrm{C}$ at a cooling rate of $5^{\circ} \mathrm{C} / \mathrm{min}$; at $20^{\circ} \mathrm{C} / \mathrm{min}$ this transformation starts at $765^{\circ} \mathrm{C}$ and finishes at about $620^{\circ} \mathrm{C}$.

\section{RS5 Heat Treatment Optimization}

Details of the standard heat treatment (HT\#1) applied to as-cast RS5 are given in Table III. The heat treatment temperatures were determined on the basis of phase diagram modeling (Figure 5) for the nominal composition of the alloy. The HIP and solution heat treatment temperatures were chosen to ensure that full solutioning of all phases in the as-cast microstructure was achieved, while being sufficiently below the solidus temperature to avoid incipient melting. A separate HIP and solution heat treatment have

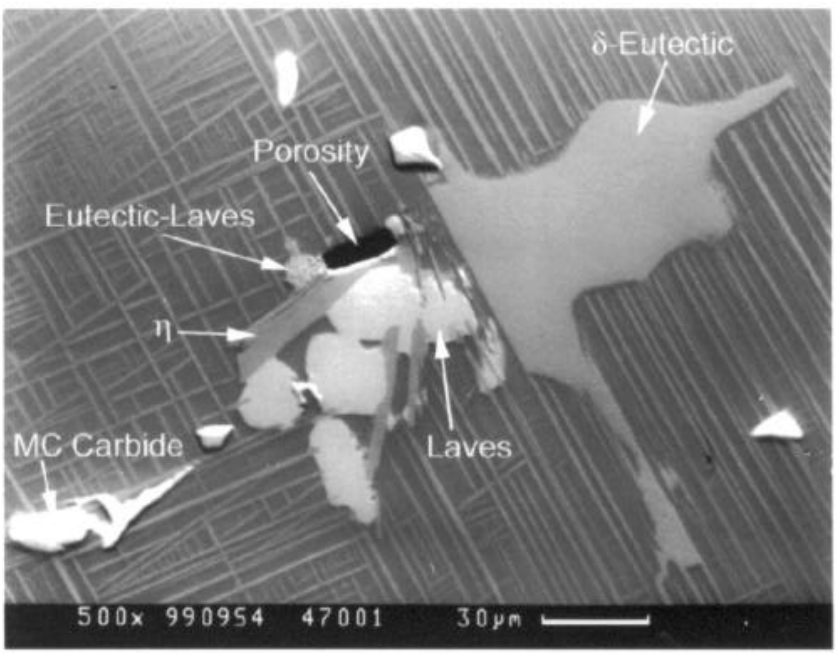

Figure 3: Solidification microstucture of an RS5 specimen cooled from liquid at $5^{\circ} \mathrm{C} / \mathrm{min}$.

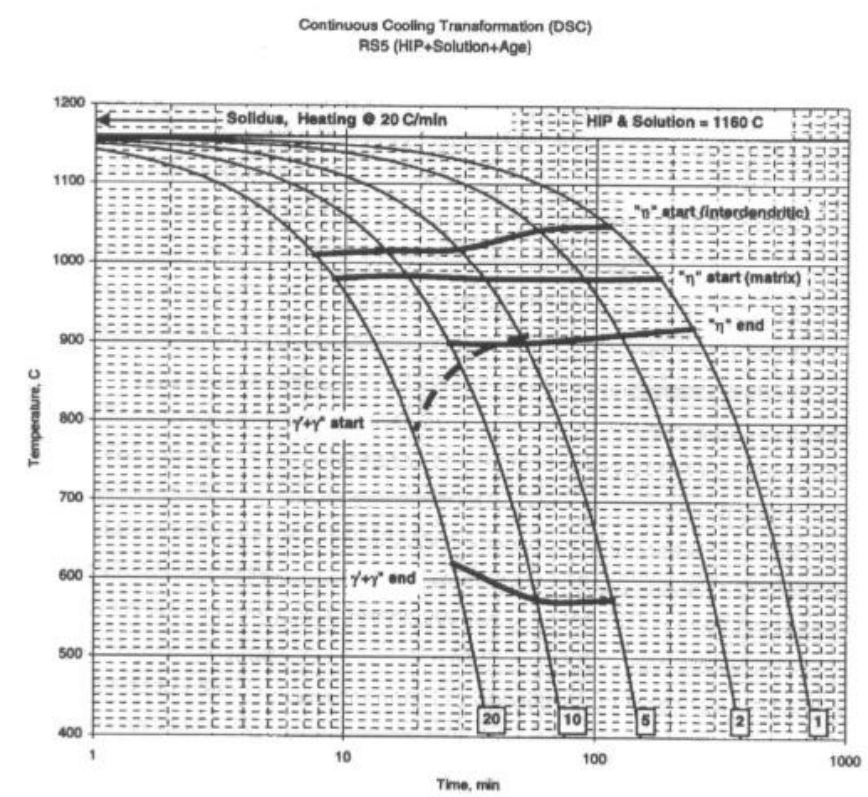

Figure 4: Continuous cooling transformation diagram for superalloy RS5.

been specified due to the limited availability of HIP facilities capable of achieving the required cooling rate of greater than $50^{\circ} \mathrm{C}$ per minute. This cooling rate is required in order to avoid $\eta$ phase precipitation during cooling from the solution temperature.

The HIP and solution heat treatment temperatures have been kept constant in this study, and the alternative heat treatments have concentrated on assessing the effect of applying an initial homogenization treatment or alternative aging temperatures. The aim of $\mathrm{HT} \# 2$, which included an $1100^{\circ} \mathrm{C}$ homogenization heat treatment, was to determine whether the additional lower temperature heat treatment was required to minimize compositional variation and prevent incipient melting in TCS cast RS5. The phase diagram model shows that $1100^{\circ} \mathrm{C}$ is still sufficient to fully solution the alloy. The aim of HT\#3 and HT\#4 was to assess alternative precipitation heat treatments. A $750^{\circ} \mathrm{C}$ aging temperature was chosen to produce a higher volume fraction of $\gamma^{\prime}$ and a lower

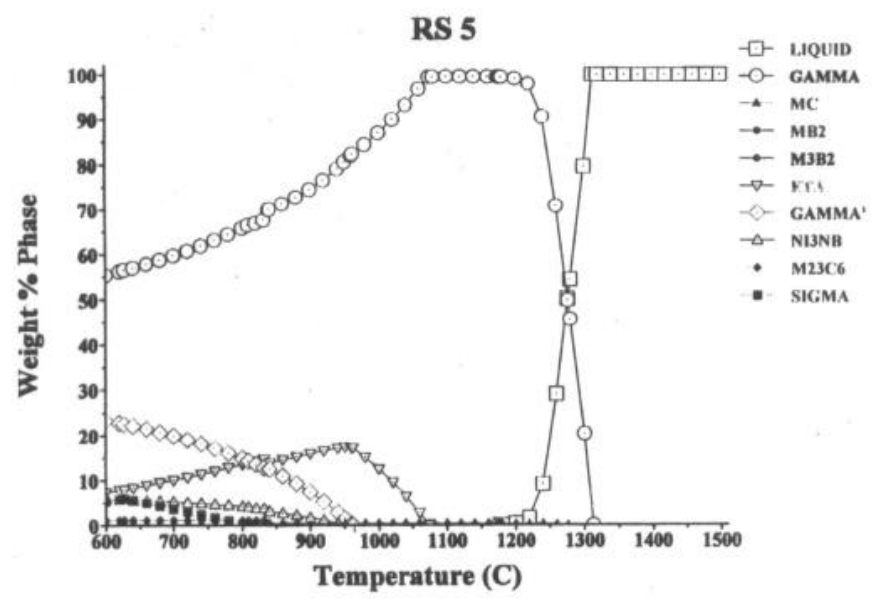

Figure 5: Phase diagram model for RS5. 
Table III Heat Treatment Variations of the RS5 Alloy

\begin{tabular}{|c|c|c|c|c|c|}
\hline Treatment & $\begin{array}{c}\text { Temperature } \\
\left({ }^{\circ} \mathrm{C}\right)\end{array}$ & $\begin{array}{c}\text { Time } \\
(\mathrm{hr})\end{array}$ & Pressure (MPa) & $\begin{array}{l}\text { Cooling rate } \\
\left({ }^{\circ} \mathrm{C} / \mathrm{min}\right)\end{array}$ & Atmosphere \\
\hline \multicolumn{6}{|c|}{$\underline{\text { HT\#1 - Standard Heat Treatment }}$} \\
\hline HIP & 1160 & 4 & 103 & & Argon \\
\hline Solution & 1160 & 4 & N/A & GFQ $(>50)$ & Vac./inert gas \\
\hline Age & 800 & 16 & N/A & Air cool & Air \\
\hline \multicolumn{6}{|c|}{$\underline{\text { HT\#2 - Homogenization Heat Treatment }}$} \\
\hline Homogenization & 1100 & 4 & N/A & GFQ (>50) & Vac./inert gas \\
\hline HIP & 1160 & 4 & 103 & & Argon \\
\hline Solution & 1160 & 4 & N/A & GFQ (>50) & Vac./inert gas \\
\hline Age & 800 & 16 & N/A & Air cool & Air \\
\hline \multicolumn{6}{|c|}{ HT\#3 - Alternative Age Heat Treatment } \\
\hline HIP & 1160 & 4 & 103 & & Argon \\
\hline Solution & 1160 & 4 & N/A & GFQ $(>50)$ & Vac./inert gas \\
\hline Age & 750 & 16 & N/A & Air cool & Air \\
\hline \multicolumn{6}{|c|}{$\underline{\text { HT\#4 - Two-Step Age Heat Treatment }}$} \\
\hline HIP & 1160 & 4 & 103 & & Argon \\
\hline Solution & 1160 & 4 & N/A & GFQ $(>50)$ & Vac./inert gas \\
\hline Age & 750 & 8 & N/A & Air cool & Air \\
\hline Age & 650 & 8 & N/A & Air cool & Air \\
\hline
\end{tabular}

volume fraction of $\eta$-phase than in the $800^{\circ} \mathrm{C}$ age used in HT\#1 and HT\#2. The purpose of a two-stage aging treatment in HT\#4 was to determine whether, as for IN718, additional $\gamma^{\prime}$ of a finer particle size would precipitate at the lower temperature.

\section{Microstructural Analysis}

Examination of RS5 in the standard heat treated condition (HT\#1) revealed that a ghost dendritic structure persisted after heat treatment of the TCS cast alloy (Figure 6). This indicates that full homogenization was not achieved. Secondary phases, such as carbide particles and irregular shaped plates that are assumed to be $\eta$-phase $(\mathrm{Ni3Ti})$ or $\delta$-phase $(\mathrm{Ni} 3 \mathrm{Nb})$, are concentrated within

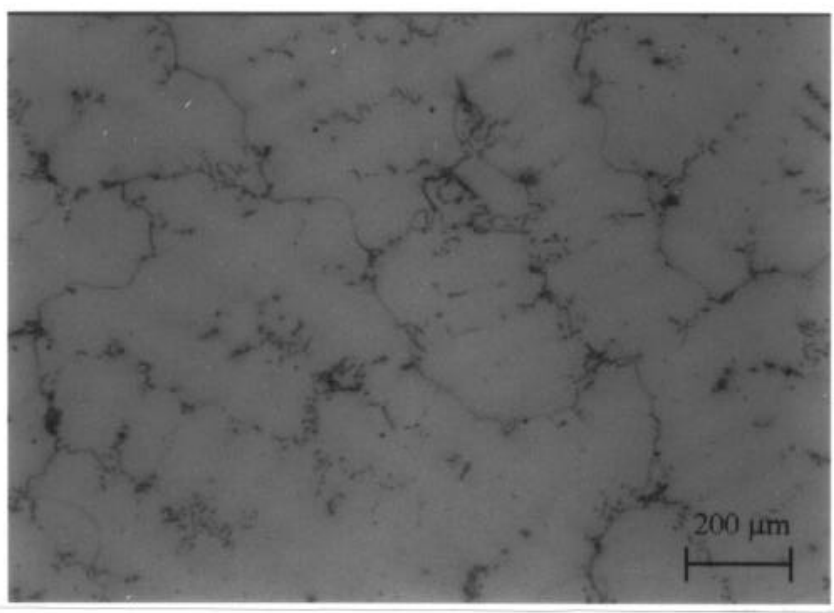

Figure 6: Optical micrograph of RS5 in the standard heat treatment condition (HT\#1). Primary grain boundaries are evident at interface between dendrites in the original as-cast structure. the interdendritic regions (Figure 7). The carbide particles are predominantly associated with primary grain boundaries, which form at the interface between dendrites in the cast structure. Hence, in the heat treated condition, grain size is strongly influenced by the dendrite spacing of the casting. Due to the nature of the dendrites, elongated grains that are as much as $1000 \mu \mathrm{m}$ long and approximately $200 \mu \mathrm{m}$ in diameter are formed. Precipitation of a phase, whose morphology is either needles or platelets (Figure 8), was observed on the primary grain boundaries. Transmission electron microscopic (TEM) examination of other

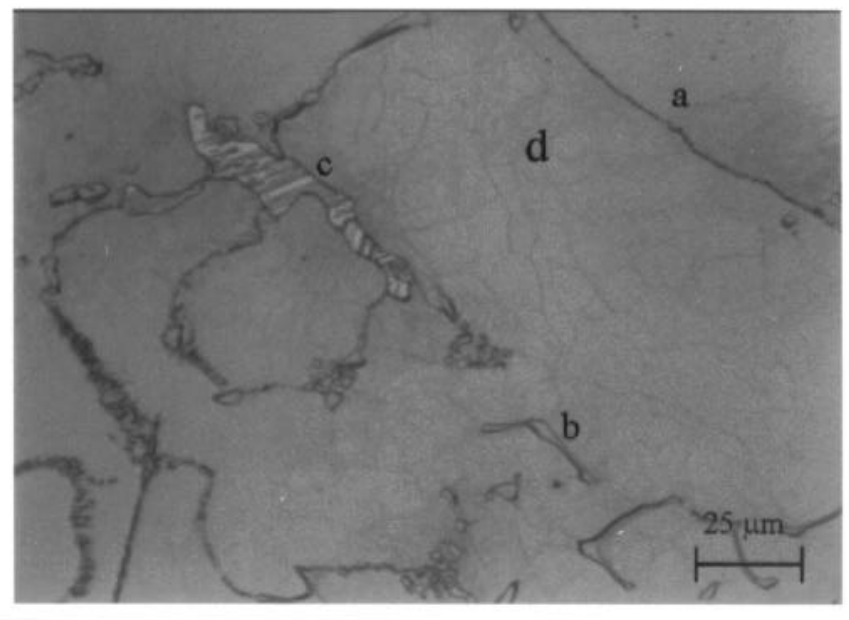

Figure 7: Optical micrograph of RS5 in the standard heat treatment condition (HT\#1). Features present in the interdendritic region are primary grain boundaries (a), carbide particles (b), $\eta$ or $\delta$ phase (c), and a subgrain structure (d). 


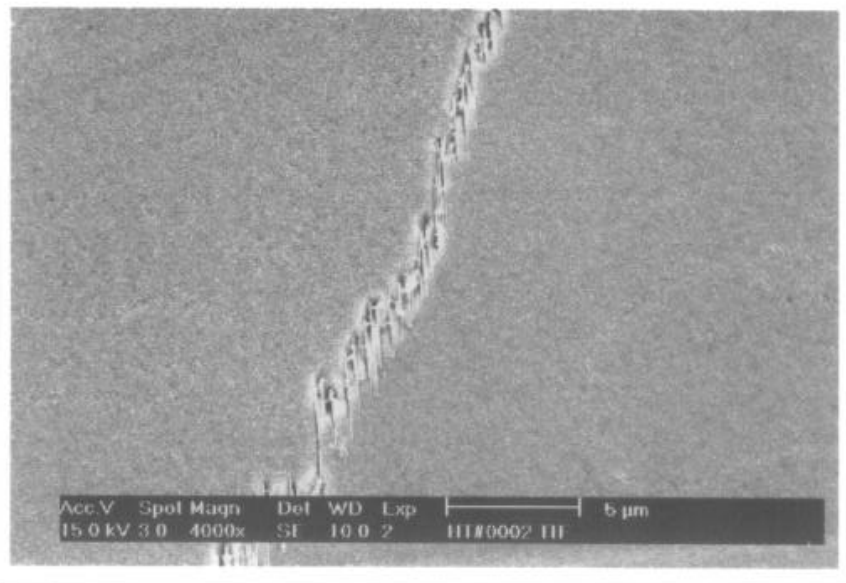

Figure 8: Secondary electron micrograph showing $\eta$-phase precipitates on a primary grain boundary in RS5, HT\#1.

forms of RS5 has shown that this phase is $\eta$-phase. It is considered unlikely that the $\eta$-phase will have a detrimental effect on the strength of the grain boundaries as it is discreet and oriented approximately perpendicular to the grain boundary. Within the interdendritic regions a subgrain structure was also apparent (Figure 7). Gamma prime particles are present on these subgrain boundaries, which are taken to indicate that an orientation mismatch exists between these local areas in the structure. The elongated morphology of the $\gamma^{\prime}$ precipitates, which appear to form a basket weave structure, is also shown in Figure 9.

Compositional analysis of the dendrite cores and interdendritic regions using SEM-EDS showed that chromium, cobalt and tungsten concentrate in the former region and niobium, titanium, molybdenum and tantalum concentrate in the latter region. Analyses were also carried out on the carbide particles present in the structure and showed that the particles contained approximately 50 atomic percent carbon together with molybdenum or niobium and traces of tantalum, titanium and silicon. This analysis indicates that the carbides are of the MC type.

The homogenization heat treatment (HT\#2) produced microstructures that were very similar to standard heat treatment (HT\#1) with no obvious differences in the size, morphology, and

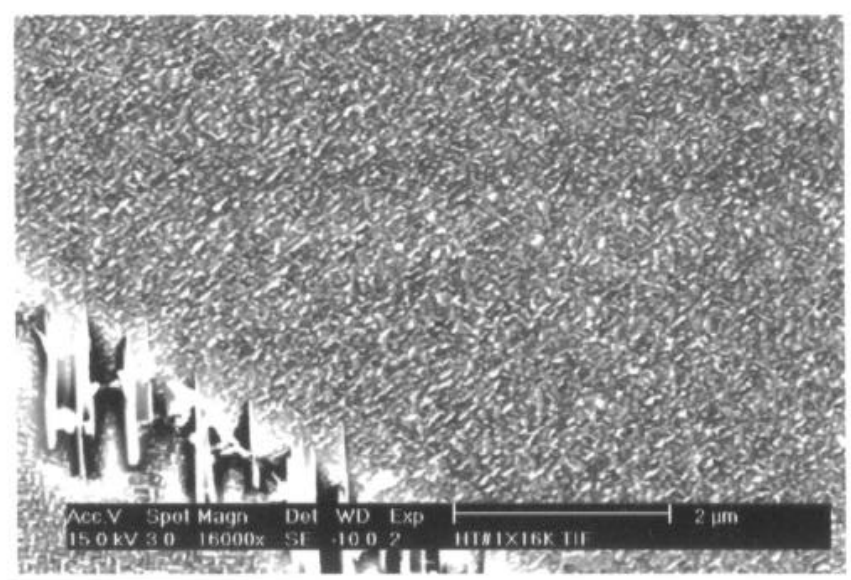

Figure 9: Secondary electron micrograph showing elongated nature of $\gamma^{\prime}$ precipitates in RS5, HT\#1. distribution of phases being readily discernible. Compositional analysis of the dendrite cores and interdendritic regions showed that the compositional variation was similar to HT\#1. These results indicate that the homogenization heat treatment was of limited benefit in minimizing compositional variation.

The RS5 samples given the alternative precipitation heat treatment (HT\#3 and HT\#4) both showed similar grain size to that of the standard heat treatment. They primarily varied from HT\#1 and HT\#2 in the morphology of the $\gamma^{\prime}$ and $\eta$-phase precipitates. The alternative precipitation heat treatment has produced $\gamma^{\prime}$ precipitates that are larger and spherical or cuboidal (Figure 10) rather than the elongated morphology formed in HT\#1 and HT\#2 (Figure 9). Also, the $\eta$-phase precipitates on the primary grain boundaries are longer and have a greater tendency to be aligned parallel with the grain boundaries. This orientation appears less favorable and suggests the possibility of a plane of weakness as compared with the essentially perpendicular orientation of the $\eta$ phase precipitates in HT\#1 and HT\#2. It was not possible at the resolution available on the SEM to determine whether the twostage aging treatment (HT\#4) had produced a bimodal $\gamma^{\prime}$ size distribution. Further studies using TEM will be carried out to determine if a finer $\gamma^{\prime}$ precipitate is present.

\section{Mechanical Property Comparisons}

The mechanical properties of the four different heat treatment variations of the TCS cast RS5 alloy were also evaluated and compared to determine the optimum heat treatment. Tensile tests were conducted over a range of temperatures from $20^{\circ} \mathrm{C}$ to $815^{\circ} \mathrm{C}$, and creep tests were conducted to measure the time to $0.2 \%$ creep strain and rupture life between $650^{\circ} \mathrm{C}$ and $815^{\circ} \mathrm{C}$. Strain-controlled low cycle fatigue (LCF) tests were also performed at an R-ratio of 0 at room temperature. The tensile results showed that the alternative aging treatments increased the yield and tensile strength of the alloy. At room temperature the yield strength of HT\#3 and HT\#4 material averaged about $35 \mathrm{MPa}$ greater than that of HT\#1 or HT\#2, and the ultimate tensile strength (UTS) was also greater by about $40 \mathrm{MPa}$. The higher yield strength persisted at $426^{\circ} \mathrm{C}$ and $600^{\circ} \mathrm{C}$ but was negligible at higher temperatures. The same trend is evident with respect to UTS. The $0.2 \%$ creep strength of RS5 subjected to the standard heat treatment (HT\#1) is greater than that of RS5 given the alternative aging treatments, and rupture strength shows the same trend. The effect is most noticeable at lower temperatures

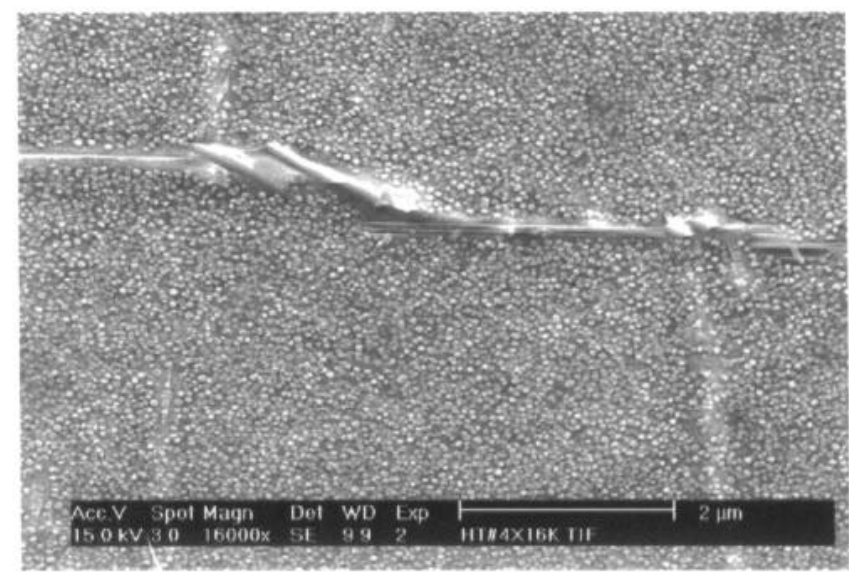

Figure 10: Secondary electron micrograph of sample HT\#4. The structure contains spherical/cuboidal $\gamma^{\prime}$ precipitates and elongated $\eta$-phase precipitates along the primary grain boundaries. 
$\left(\sim 650^{\circ} \mathrm{C}\right)$ and higher stresses. The four different heat treat conditions demonstrated no discernible differences in LCF behavior at room temperature.

Based on the results of the microstructural examination and mechanical property evaluation, the decision was made to characterize the RS5 alloy further only in the standard heat treatment condition (HT\#1). The data shown in the remainder of the paper reflect the behavior of this heat treatment condition only.

\section{Thermal Stability}

Previous mechanical property evaluations of various forms of RS5 have revealed that during creep testing at the highest use temperature of the alloy a phase instability occurs in the microstructure [4]. Time, temperature, and stress are required to initiate this phase instability. To determine the extent to which TCS cast RS5 is prone to this phenomenon a series of creep tests were performed on the alloy for approximately $500 \mathrm{hr}$ at $600^{\circ} \mathrm{C} /$ $750 \mathrm{MPa}, 700^{\circ} \mathrm{C} / 400 \mathrm{MPa}$, and $800^{\circ} \mathrm{C} / 150 \mathrm{MPa}$. On completion of the creep tests, the samples were longitudinally sectioned, mounted, polished, and etched for microstructural evaluation. The same creep tests and microstructural analysis were performed on TCS cast IN939 for comparison with the RS5 alloy.

\section{$\underline{\text { RS5 }}$}

Microstructural evaluation of RS5 following creep testing showed that at both $700^{\circ} \mathrm{C}$ and $800^{\circ} \mathrm{C}$ the ghost dendritic structure in alloy progressively decreased, and that coarsening of the $\gamma^{\prime}$ precipitates occurred, indicating that elemental diffusion, which is enhanced by the presence of stress, had occurred. The most dramatic change in the microstructure occurred on testing at $800^{\circ} \mathrm{C}$. At this temperature an acicular phase was observed to precipitate in the microstructure (Figure 11). The density of the acicular phase was greatest in the interdendritic regions, with only a limited number of precipitates observed in the dendrites. Previous studies on a different form of RS5 have identified the precipitates as $\delta$-phase. This phase was observed to precipitate on and grow from the $\eta$ precipitates that are present on the grain boundaries in the alloy. The higher density of delta phase in the interdendritic region reflects the higher niobium content in this region, while the absence of precipitates in the dendrite cores indicates the lower niobium content and the absence of a composition gradient in this region of the structure.

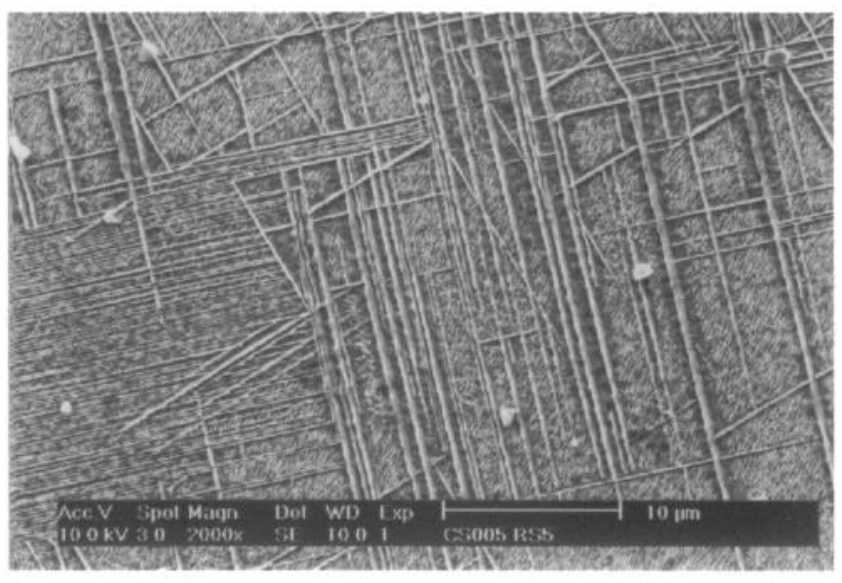

Figure 11: Acicular $\delta$-phase precipitates in interdendritic region of RS5, HT\#1 following creep testing at $800^{\circ} \mathrm{C} / 150 \mathrm{MPa}$ for about $500 \mathrm{hr}$.
A temperature of $800^{\circ} \mathrm{C}$ is at the upper temperature limit at which RS5 was designed to operate. Although fundamentally the phase instability and acicular nature of the delta phase are undesirable, the predominant strengthening phase in the alloy, $\gamma^{\prime}$, has not been denuded by the phase change. Information in the literature for René220C [3] indicates that the $\delta$-plate structure can be controlled to influence fatigue and effectively impede fatigue crack propagation. Additionally, preliminary studies to determine the residual strength of creep tested spray-formed RS5 [4] containing the $\delta$ phase have shown that the phase has minimal influence on the strength and ductility as compared with the base tensile properties for the alloy. This information indicates that, although undesirable, the formation of delta phase does not have a significant influence on the mechanical properties of the alloy.

\section{IN 939}

Microstructural evaluation of IN939 following creep testing showed that the ghost dendritic structure persisted in the microstructure on creep testing and that coarsening of the $\gamma^{\prime}$ precipitates did not occur. No phase instability was observed in the alloy in the temperature range studied. These observations with the mechanical property results, described in detail later, show that IN939, while having a lower strength, offers a higher temperature capability than RS5. Phase instabilities in IN939 are, therefore, likely to arise at higher temperatures than assessed in the current study.

\section{Mechanical Behavior of TCS Cast Alloys}

The purpose of the mechanical testing conducted in this study was, first, to compare the properties of the TCS cast alloys: IN718, IN939, and RS5; and, second, on a limited basis, to compare the TCS cast alloy properties with those for the same alloy conventionally investment cast." The mechanical behavior of the TCS cast alloys was evaluated with respect to tensile, creep, LCF, and room temperature fatigue crack growth (FCG) behavior. In addition, the elevated temperature FCG performance of the RS5 alloy was characterized. Table IV shows the test matrix with all test conditions. The tensile, creep, and LCF specimens were cast-to-size hung-on-bars (HOBs) that were machined prior to testing. The FCG testing was performed on compact tension specimens, nominally $6 \mathrm{~mm}$ in thickness, that were sectioned from a TCS cast plate.

\section{Tensile Properties}

Figure 12 illustrates the yield and ultimate tensile strength of the three TCS cast alloys. The data shown are the average of three tests for each alloy at each temperature tested. The RS5 alloy demonstrated higher tensile strength than IN939 or IN718 across the entire temperature range investigated. The yield strength of RS5 was also superior to the other two alloys. However, while IN718 showed the lowest UTS, its yield strength was significantly greater $(\sim 150 \mathrm{MPa})$ than IN939. The yield and ultimate tensile strength of conventionally cast IN718 are included in Figure 12. The yield strength of the TCS cast IN718 is about $100 \mathrm{MPa}$ greater than that for the conventionally cast alloy. This improvement is likely related to the finer grain size that results from TCS casting. The tensile ductility of the TCS alloys and conventionally cast IN718 was also measured. From room temperature to $600^{\circ} \mathrm{C}$ the reduction in area for RS5 and IN939 is between 8 and $10 \%$, approximately half that for the TCS cast IN718, which is in turn about half that for the conventionally cast IN718 alloy.

- The data for the conventionally cast material was derived from Roll-Royce databases and was not produced as part of this program. 
Table IV Mechanical Property Test Matrix for TCS Casting Process Assessment

\begin{tabular}{|c|c|c|c|c|c|}
\hline Alloy & Condition & Test & Temperature $\left({ }^{\circ} \mathrm{C}\right)$ & Tests/temp & Total tests \\
\hline $\begin{array}{l}\text { IN718 } \\
\text { IN939 } \\
\text { RS5 }\end{array}$ & $\begin{array}{l}\text { TCS + HIP + heat treat } \\
\text { TCS + HIP + heat treat } \\
\text { TCS + HIP + heat treat \#1 }\end{array}$ & Tensile & $21,427,593,704,815$ & $\begin{array}{l}3 \\
3 \\
3 \\
\end{array}$ & $\begin{array}{l}15 \\
15 \\
15\end{array}$ \\
\hline $\begin{array}{l}\text { IN718 } \\
\text { IN939 } \\
\text { RS5 }\end{array}$ & $\begin{array}{l}\text { TCS + HIP + heat treat } \\
\text { TCS + HIP + heat treat } \\
\text { TCS + HIP + heat treat \#1 }\end{array}$ & Creep & $650,704,760,815$ & $\begin{array}{l}3 \\
3 \\
3\end{array}$ & $\begin{array}{l}12 \\
12 \\
12\end{array}$ \\
\hline $\begin{array}{l}\text { IN718 } \\
\text { IN939 } \\
\text { RS5 }\end{array}$ & $\begin{array}{l}\text { TCS + HIP + heat treat } \\
\text { TCS + HIP + heat treat } \\
\text { TCS + HIP + heat treat \#1 }\end{array}$ & $\begin{array}{l}\mathrm{LCF}, \mathrm{R}=0, \mathrm{Kt}=1.0 \\
\text { Freq. }=20 \mathrm{cpm} \\
\text { Strain control }\end{array}$ & $21,427,650$ & $\begin{array}{l}5 \\
5 \\
5 \\
\end{array}$ & $\begin{array}{l}15 \\
15 \\
15\end{array}$ \\
\hline $\begin{array}{l}\text { IN718 } \\
\text { IN939 } \\
\text { RS5 }\end{array}$ & $\begin{array}{l}\text { TCS + HIP + heat treat } \\
\text { TCS + HIP + heat treat } \\
\text { TCS + HIP + heat treat \#1 }\end{array}$ & $\begin{array}{l}\text { FCG, } R=0.05 \\
\text { Freq. }=15 \mathrm{cpm}\end{array}$ & $\begin{array}{l}21 \\
21 \\
21,427,650\end{array}$ & $\begin{array}{l}2 \\
2 \\
2\end{array}$ & $\begin{array}{l}6 \\
6 \\
6\end{array}$ \\
\hline
\end{tabular}

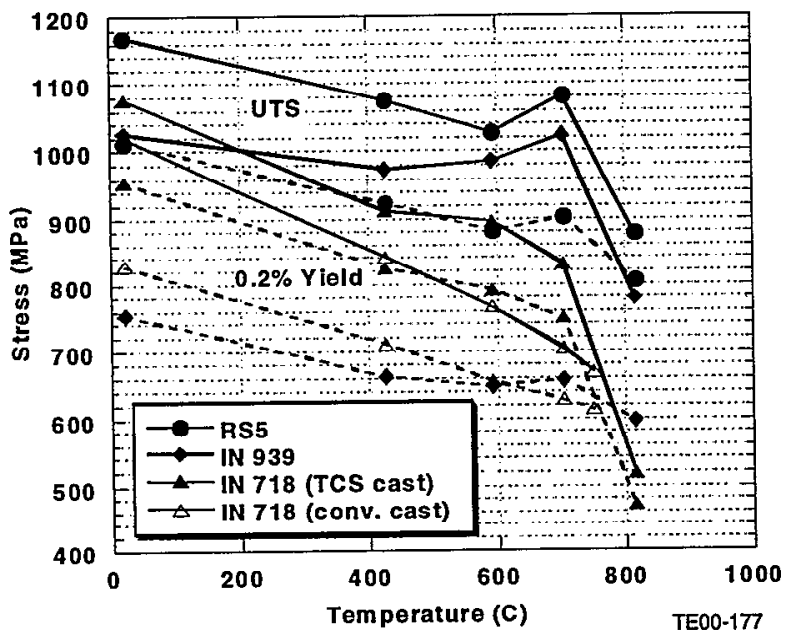

Figure 12: Yield and tensile strength of TCS cast alloys

\section{Creep Properties}

It is evident in Figure 13 that TCS cast RS5 clearly demonstrated superior creep resistance to $0.2 \%$ creep strain between $250 \mathrm{MPa}$ and $800 \mathrm{MPa}$. At $700 \mathrm{MPa}$ for a $1000-\mathrm{hr}$ creep life to $0.2 \%$ strain, the TCS cast RS5 was approximately $75^{\circ} \mathrm{C}$ better than IN939 and $180^{\circ} \mathrm{C}$ better than conventionally cast RS5. At $500 \mathrm{MPa}$ for a 1000 -hr creep life to $0.2 \%$ strain, $\mathrm{RS} 5$ shows a $45^{\circ} \mathrm{C}$ improvement over IN939 and a $60^{\circ} \mathrm{C}$ improvement over TCS cast IN718. At $250 \mathrm{MPa}$ IN939 and conventionally cast RS5 have equivalent $0.2 \%$ creep life to TCS cast RS5. In the case of stress-rupture (Figure 14), TCS cast RS5 is also superior to the other TCS cast alloys from $500 \mathrm{MPa}$ to $800 \mathrm{MPa}$ and to conventionally cast RS5 at stresses of $350 \mathrm{MPa}$ and higher. At lower stresses and higher temperatures IN939 demonstrates superior stress-rupture properties to RS5. As would be expected, both conventionally and TCS cast IN718 show significantly reduced stress-rupture life across the entire temperature range of interest.

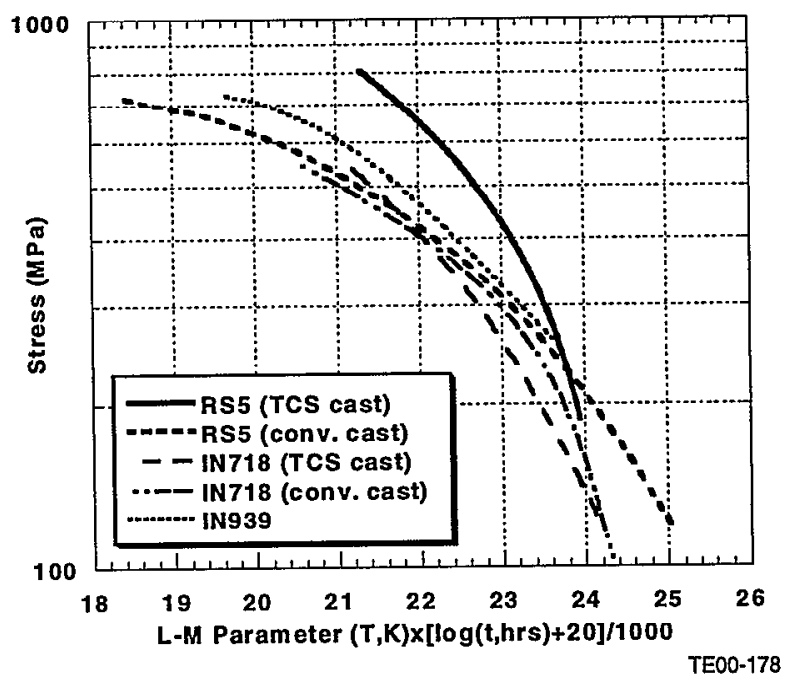

Figure 13: The $0.2 \%$ creep strain behavior of TCS cast alloys compared to conventionally cast IN718 and RS5.

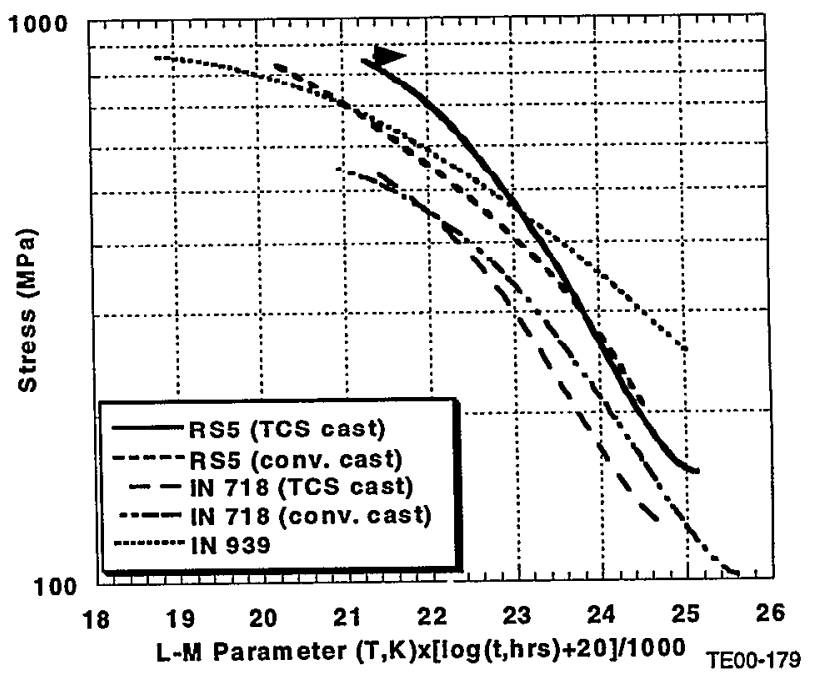

Figure 14: Stress-rupture behavior of TCS cast alloys compared to conventionally cast IN718 and RS5. 


\section{LCF Performance}

LCF tests were conducted in strain control on unnotched $\left(K_{T}=1.0\right)$ specimens at an $R$-ratio of zero. The test frequency was $20 \mathrm{cpm}$, and the wave form was triangular. Five tests were conducted for each alloy at each temperature. There was litle difference in the room temperature LCF performance of the TCS cast alloys; Figure 15 illustrates the trend in room temperature LCF for RS5, IN939, and IN718. At the elevated temperatures tested, however, some differences in performance did emerge. At $427^{\circ} \mathrm{C}$ (Figure 15), it is evident that at strain ranges greater than $0.6 \%$ TCS cast IN718 demonstrated the longest life. At lower strain ranges and lives greater than 10,000 cycles TCS cast RS5 and conventionally cast IN718 were superior. At $650^{\circ} \mathrm{C}$, the highest temperature tested (Figure 16), RS5 showed superior LCF life over all strain ranges tested, and IN939 demonstrated better performance than IN718, as expected.

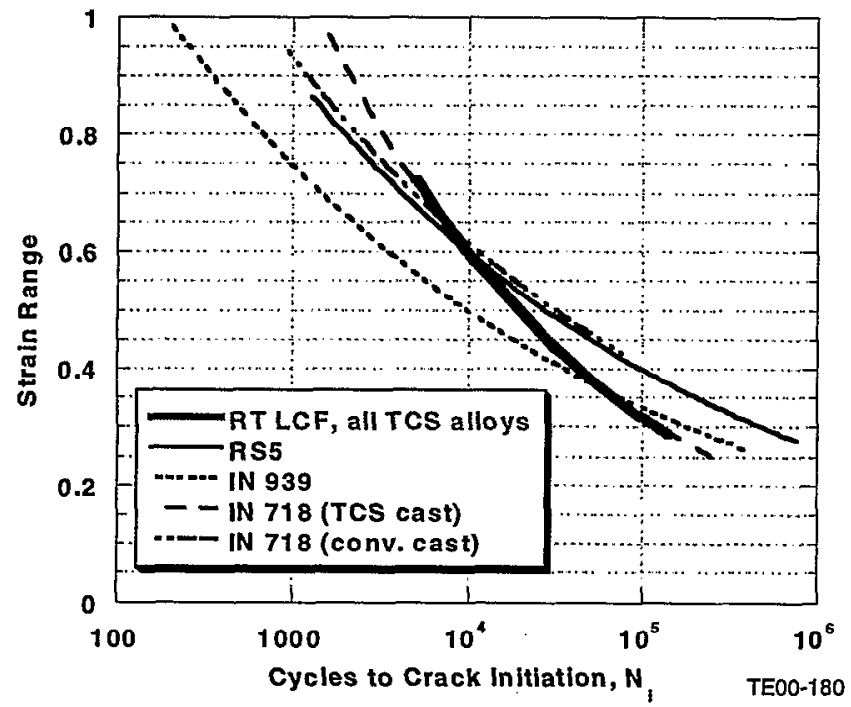

Figure 15: Strain-controlled LCF behavior of TCS cast alloys at room temperature and $427^{\circ} \mathrm{C}$.

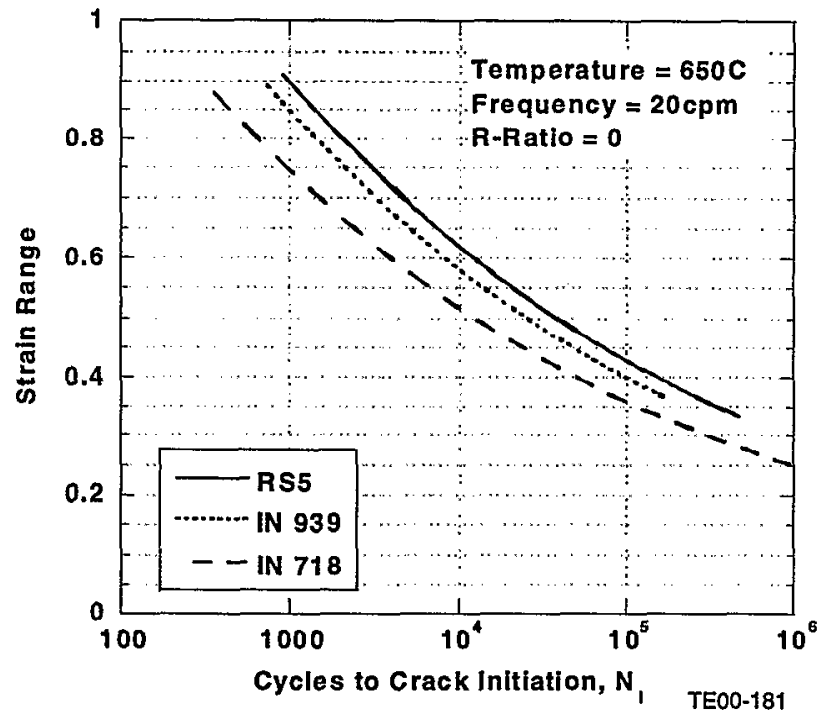

Figure 16: Strain-controlled LCF performance of TCS cast alloys at $650^{\circ} \mathrm{C}$

\section{Fatigue Crack Growth Behavior}

All the FCG tests, at both room and elevated temperature, were conducted using a trapezoidal wave form: $1 \mathrm{sec}$ hold at minimum stress, $1 \mathrm{sec}$ increase to maximum stress, $1 \mathrm{sec}$ hold at maximum stress, and $1 \mathrm{sec}$ unload to minimum stress. The R-ratio was constant at 0.05 , and crack length was monitored both visually and using electropotential drop. All tests were conducted in accordance with ASTM specification E647-93 [5]. The alloys' steady-state FCG behavior at room temperature was similar; this behavior is as expected for cast superalloys with similar grain size. RS5 was the only alloy tested at elevated temperature, and the alloy demonstrated an increase in FCG rate at constant stress intensity with increasing temperature (Figure 17). At a stress intensity of $20 \mathrm{MPa}(\mathrm{m})^{1 / 2}$ there was an order-of-magnitude increase in crack growth between room temperature and $650^{\circ} \mathrm{C}$.

\section{Summary}

The goal of the analyses presented here was to determine the optimum alloy with which to proceed with component development. The selection was made by evaluating the relative difficulty in casting and repairing the alloys via the TCS process, measuring thermal stability, and developing a preliminary mechanical property database as described previously. Castability and weld reparability are considercd vital to production of these castings at minimal cost, the main thrust of the program. Thermal stability and adequate creep and LCF performance are required to maximize component life in the use environment. High tensile strength in the superalloy selected is necessary to produce a specific strength comparable to Ti-6242S.

The RS5 alloy was selected as the optimum alloy with which to continue the component demonstration. All three alloys evaluated demonstrated adequate castability and were weld repairable. The RS5 alloy demonstrated the best capability to fill thin walls, which is essential for the diffuser case being investigated in this

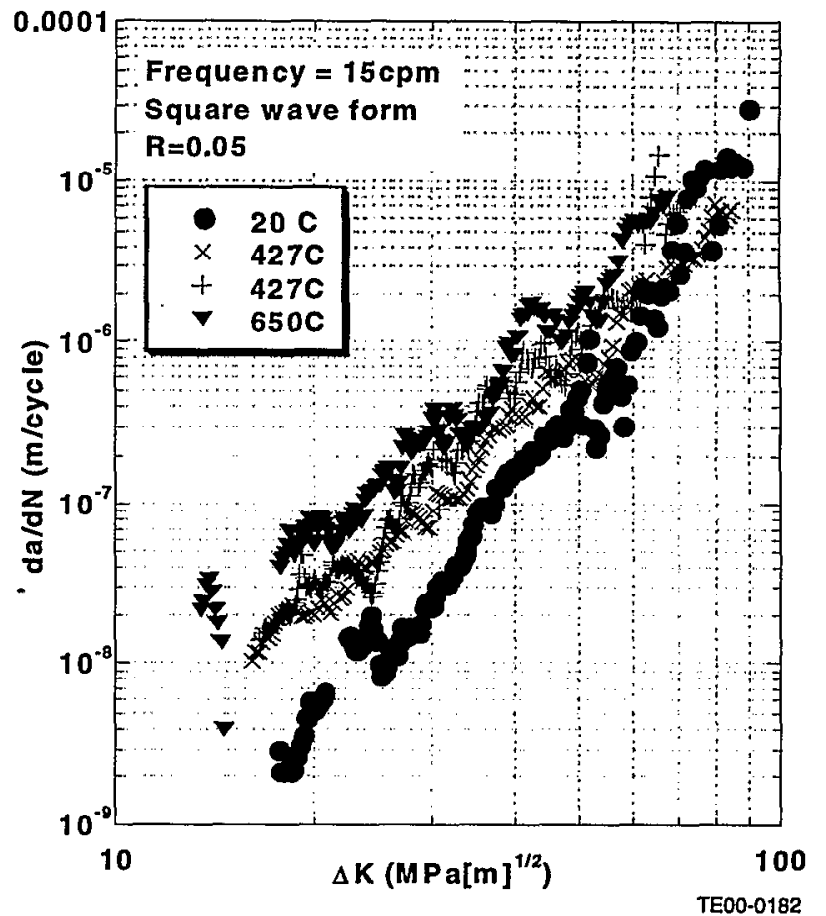

Figure 17: FCG behavior of TCS cast RS5 at room temperature, $427^{\circ} \mathrm{C}$, and $650^{\circ} \mathrm{C}$. 
program and many other structural components. While RS5 showed a propensity toward hot tear in certain casting configurations, the non-concentric ring casting was more representative of the component under consideration, and RS5 demonstrated the minimal hot tear in that casting. The thermal stability of the RS5 alloy was also adequate in the temperature range of interest $\left(400^{\circ} \mathrm{C}\right.$ to $\left.700^{\circ} \mathrm{C}\right)$, although the IN939 alloy was stable to significantly higher temperatures and would probably have been selected if the use temperature range was higher for the component. The most significant determiners among the mechanical properties evaluated were yield and tensile strength. The TCS cast RS5 alloy is clearly superior in strength to both IN718 and IN939 (Figure 12); it also has the highest specific strength of the three alloys and that most similar to Ti-6242S. RS5 was chosen because the goal of weight neutrality with the current component design is paramount to implementation of this technology in this program. Other structural applications with less stringent weight and lower temperature requirements would likely be less costly TCS cast in IN718. The RS5 alloy clearly fills a niche for parts with higher performance requirements than IN718 can fulfill and in a use temperature range below that for which IN939 is optimized. Because RS5 is TCS castable and weldable, the cost benefits derived through application of the process will be maintained with this new alloy.

\section{Acknowledgments}

The authors would like to acknowledge the U.S. Navy and the National Center for Excellence in Metalworking Technology, operated by Concurrent Technologies Corporation. This work was funded under contract No. N00140-92-C-BC49 to the U.S. Navy as part of their Manufacturing Technology Program.

\section{References}

1. S. B. Shendye, "Report on Task 3: Assessment of Thin-wall Castability of Candidate Alloys" (Report to Concurrent Technologies Corporation for Contract No. N00140-92-CBC49, PCC Structurals, Inc., 3 August 1999).

2. S. B. Shendye et al., "The Castability and Mechanical Properties of Nickel Superalloys Cast using Thermally Controlled Solidification" (Paper presented at the TMS 2000 129th Annual Meeting and Exhibition, Nashville, TN, 12-16 March 2000).

3. S. T. Wlodek and R. D. Field, "The Structure of René 220C," Superalloys 1992, ed. S. D. Antolovich et al. (Warrendale, PA: The Minerals, Metals \& Materials Society, 1992), 477-486.

4. P. Andrews, unpublished research, Rolls-Royce Derby, UK, 22 August 1997.

5. "Standard Test Method for Measurement of Fatigue Crack Growth Rates," Annual Book of ASTM Standards, vol. 3.01 (Philadelphia, PA: ASTM, 1993), 679-706. 